\title{
ANALISIS BIAYA PANEN DAN PASCA PANEN CENGKEH DI DESA KAWENG KECAMATAN KAKAS KABUPATEN MINAHASA
}

\author{
Rain Panekenan \\ Caroline B. D. Pakasi \\ Lyndon R. J. Pangemanan
}

\begin{abstract}
This study aims to analyze the cost of harvest and post-harvest cloves. This research was conducted in Kaweng Village Kakas Subdistrict of Minahasa Regency and lasted from July until September 2016. The research method used in this research is survey method. Data collection method in this research is by using primary data and secondary data. Sampling method is by using simple random sampling method. The data analysis used is the data collected tabulated by using cost analysis. The results of this study was that each harvest activity costs vary, it is issued in accordance with the needs of farmers to support harvest and post-harvest activities for 2-3 months during the 1st harvest and post harvest period. The largest average is at the cost of picking of Rp.222.352.500. Each production was influenced by variable costs and fixed costs at one time of production at the price of the cloves present at harvest, where the variable cost amounts to Rp.360.243.500 and fixed costs Rp.1.866.000 in production amount of $8.677 \mathrm{~kg}$ with an average price of Rp.106.050 per kg.*jnk*.
\end{abstract}

Keywords: cost analysis, harvest and post harvest, cloves, Kaweng Village, Kakas Subdistrict, Minahasa Regency.

\begin{abstract}
ABSTRAK
Penelitian ini bertujuan untuk menganalisis biaya panen dan pasca panen cengkeh. Penelitian ini dilakukan di Desa Kaweng Kecamatan Kakas Kabupaten Minahasa dan berlangsung selama bulan Juli sampai bulan September 2016. Metode penelitian yang digunakan dalam penelitian ini adalah metode survey. Metode pengumpulan data dalam penelitian ini adalah dengan menggunakan data primer dan data sekunder. Metode pengambilan sampel yaitu dengan menggunakan metode simple random sampling. Analisis data yang digunakan adalah data yang dikumpulkan ditabulasikan dengan menggunakan analisis biaya. Hasil penelitian ini adalah setiap kegiatan panen mengeluarkan biaya yang bervariasi, hal tersebut dikeluarkan sesuai dengan kebutuhan para petani guna menunjang kegiatan panen dan pasca panen selama 2 - 3 bulan selama dalam 1 periode panen dan pasca panen. Rata - rata terbesar terdapat pada biaya saat pemetikan sebesar Rp. 222.352.500. Setiap produksi dipengaruhi oleh biaya variabel dan biaya tetap pada satu kali produksi dengan harga cengkeh yang ada pada saat panen, dimana jumlah biaya variabel sebesarr Rp.360.243.500 dan biaya tetap Rp.1.866.000 pada jumlah produksi $8.677 \mathrm{~kg}$ dengan rata - rata harga Rp.106.050 per kg. *jnkd*.
\end{abstract}

Kata kunci: analisis biaya, panen dan pasca panen, cengkeh, Desa Kaweng, Kecamatan Kakas. 


\section{PENDAHULUAN}

\section{Latar Belakang}

Cengkeh (Syzgium aromaticum, syn eugenia armoaticum), dalam bahasa inggris disebut Cloves adalah tangkai bunga kering beraroma dari keluarga pohon Myrtaceae merupakan komoditi yang mempunyai nilai ekonomi yang tinggi dan berpeluang untuk dikembangkan dalam rangka memperbesar pendatapan negara dan meningkatkan pendapatan petani. Komoditi ini banyak digunakan dibidang industri sebagai bahan pembuatan rokok kretek sedangkan minyak cengkeh kering digunakan sebagai bahan baku industri farmasi, penyedap masakan dan wewangian.

Sulawesi Utara merupakan daerah yang sebagian besar penduduknya bekerja dari sektor pertanian. Sulawesi Utara juga merupakan daerah penghasil produk - produk pertanian yaitu tanaman holtikultura, tanaman pangan dan tanaman perkebunan, salah satu tanaman yang dihasilkan di daerah ini adalah cengkeh. Hasil tanaman cengkeh banyak diperdagangakan terutama untuk konsumen pabrik rokok kretek dan juga digunakan sebagai bahan dasar pembuatan obat - obatan (Hadiwijaya, 1982).

Kabupaten Minahasa khususnya Kecamatan Kakas merupakan salah satu daerah penghasil cengkeh dan desa kaweng adalah daerah yang memiliki Luas Wilayah 12,50 km (Area) potensi Sumber Daya Manusia (SDM) yang cukup mencapai 1.629 jiwa dan mmemiliki potensi wilayah yang luas mencapai 1.149 ha, dengan jumlah perangkat yang cukup sehingga penyelenggaraa pemerintah desa bisa berjalan dengan baik. Pada umumnya wilayah Kabupaten Minahasa merupakan penghasil terbesar komoditi cengkeh yang ada di Sulawesi Utara termasuk Desa Kaweng. Pada bulan juli masyarakat Desa Kaweng melakukan panen cengkeh dan sebagian besar masyarakat mempunyai lahan cengkeh sendiri. Lahan yang dikelola petani cengkeh ada yang milik sendiri tapi juga milik orang lain sehingga pendapatan usahatani yang peroleh ada yang diperoleh tidak sepenuhnya milik petani itu (Mandei, Laoh dan Wuisan, 2010). Banyaknya kebun cengkeh yang dimiliki petani belum merupakan jaminan tingginya petani pendapatan petani. Hal ini disebabkan karena harga cengkeh yang tidak stabil dan musim bunga cengkeh yang juga tidak stabil. Kebanyakan petani memilih untuk tidak memanen bunga cengkeh pada saat musim bunga cengkeh sedikit, mereka berpikir bahwa dengan jumlah bunga cengkeh sedikit maka jumlah biaya yang akan mereka keluarkan akan besar. Oleh karena itu pendapatan petani cengkeh yang ada di Desa Kaweng bervariasi. Kemampuan petani dalam mengalokasikan biaya secara efisien akan menentukan tingkat pendapatan yang diperolehnya, ini berarti bahwa petani harus mampu mengalokasikan biaya agar supaya pendapatan yang dihasilkan masih lebih tinggi dari biaya yang dikeluarkan (Rantung, 2002).

Biaya panen atau pasca panen cegkeh merupakan biaya yang harus dikeluarkan selama masa panen cengkeh berlangsung. Dengan memperhitungkan keseluruhan biaya yang dikeluarkan saat panen maka akan diketahui berapa besar biaya pengeluaran petani dan petani dapat mengetahui berapa besar selisih harga cengkeh dengan biaya pengeluaran saat panen cengkeh berlangsung. Dengan demikian penelitian ini meneliti berapa besar pengeluaran petani pada saat panen cengkeh. Biaya panen atau pasca panen di Desa Kaweng meliputi: Tenaga kerja, Perlengkapan, dan Konsumsi.

\section{Rumusan Masalah}

Berapa besar biaya yang dikeluarkan petani pada saat panen dan pasca panen cengkeh di Desa Kaweng Kecamatan Kakas Kabupaten Minahasa.

\section{Tujuan Penelitian}

Peneilitian ini bertujuan untuk mengetahui biaya panen dan pasca panen cengkeh di Desa Kaweng Kecamatan Kakas Kabupaten Minahasa.

\section{Manfaat Penelitian}

Penelitian ini diharapkan dapat menjadi bahan masukan dan pertimbangan bagi petani dalam mengelolah usaha tani khususnya panen cengkeh dan menjadi referensi bagi penelitian selanjutnya. 


\section{METODE PENELITIAN}

\section{Waktu dan Tempat Penilitian}

Penelitian ini berlangsung selama 4 bulan yaitu sejak bulan Juni sampai bulan September 2016, dari perisapan penyusunan laporan hasil penilitian. Penilitian ini dilakukan di Desa Kaweng Kecamatan Kakas.

\section{Metode Pengambilan Data}

Data yang digunakan dalam penilitian ini adalah data primer yang hasil dioperoleh dari wawancara dengan petani, dan data sekunder diperoleh melalui instansi-instansi yang terkait.

\section{Metode Pengambilan Sampel}

Metode pengambilan sampel yang dipilih ada simple random sampling atau pengambilan sampel secara acak. Jumlah sampel yang diambil adalah 20 sampel petani.

\section{Konsep Pengukuran Variabel}

Variabel yang di ukur dalam penelitian ini adalah.

A. Karakteristik petani :

1. Umur

2. Tingkat pendidikan (SD, SMP, SMA, Perguruan Tinggi)

3. Luas lahan yaitu luas yang ditanam petani (ha)

4. Tanggungan keluarga

B. Harga (price), yaitu harga jual dari hasil panen cengkeh.

C. Jenis - jenis biaya pada proses panen

1. Konsumsi

2. Tenaga Kerja (Luar Desa dan Dalam Desa)

3. Transportasi

4. Tangga

5. Saloi

6. Karung Goni

7. Terpal

8. Ayakan Cengkeh

9. Alat Penampi

10. Karung Plastik

11. Produksi

Jenis - jenis biaya pada proses pasca panen

1. Pajak / (pertahun)

2. Produksi

3. Penjemuran / Pengeringan

4. Tenaga Kerja
5. Terpal

6. Karung Goni

7. Ayakan

8. Alat Penampi

9. Konsumsi

10. Transportasi

\section{Analasis Data}

Data yang dikumpulkan kemudian ditabulasikan dengan menggunakan analisis biaya, selanjutnya ditabelkan dan dideskripsikan.

Dengan perhitungan: $\quad \mathrm{B}=\mathrm{BT}+\mathrm{BV}$

$$
\begin{aligned}
\mathrm{PT} & =\mathrm{P} \times \mathrm{H} \\
\mathrm{Y} & =\mathrm{PT}-\mathrm{B}
\end{aligned}
$$

Keterangan: $\mathrm{BV}=$ Biaya Variabel

$$
\begin{aligned}
\text { BT } & =\text { Biaya Tetap } \\
\text { B } & =\text { Biaya Total } \\
\text { H } & =\text { Harga Jual } \\
\mathrm{P} & =\text { Produksi Cengkeh } \\
\text { PT } & =\text { Penerimaan Total } \\
\mathrm{Y} & =\text { Pendapatan }
\end{aligned}
$$

\section{HASIL DAN PEMBAHASAN}

\section{Deskripsi Umum}

Secara garis besar deskripsi umum merupakan penjelasan umum tentang suatu hal. Deskripsi bagian merupakan paragraf yang mengandung bagian bagian dari suatu objek yang tengah kita amati.

\section{Letak dan Luas Wilayah Penelitian}

Kecamatan Kakas adalah wilayah kabupaten Minahasa yang terletak di bagian selatan dan barat danau Tondano terletak diantara: Lintang Utara : $0^{0} 13^{\prime}-1^{0} 16^{\prime}$ '

Bujur Timur : $124^{0} 51^{\prime}-125^{\circ} 05^{\prime}$

Yang berbatasan dengan:

a. Sebelah Utara dengan Danau Tondano

b. Sebelah Timur dengan kecamtan Lembean Timur dan kecamatan Eris

c. Sebelah selatan dengan laut Maluku

d. Sebelah Barat dengan kecamatan Kakas Barat

Luas wilayah kecamatan kakas adalah $73,55 \mathrm{~km}^{2}$, terdiri dari 13 desa, salah satunya merupakan Desa Kakas Kaweng yang merupakan lokasi Penelitian dengan Luas wilayah dan Presentase Desa Kakas Kaweng di Kecamatan Kakas Tahun 2015. 12,50 $\mathrm{km}^{2} / 17,00 \%$. 


\section{Penduduk}

Penduduk adalah orang-orang yang berada di dalam satu wilayah yang terkait oleh aturanaturan berlaku dan saling berinteraksi satu sama lain secara terus menerus. Dalam sosiologi, penduduk adalah kumpulan manusia yang menepati suatu wilayah geografi dan tataruang tertentu (Amalia, 2008). Jumlah penduduk Desa Kakas Kaweng sampai tahun 2016 adalah 1.676 jiwa terdiri dari 877 laki-laki dan 799 perempuan dengan jumlah kepala keluarga 504. Berdasarkan monografi desa, tingkat pendidikan terbanyak pada tamatan SMP, disusul dengan tamatan SD Kemudian SMA dan S1. Sarana pendidikan yang tersedia berjumlah 3 sarana yaitu satu TK Swasta, satu SD Swasta dan satu SD Negri.

Penduduk desa Kakas Kaweng Mayoritas beragama Kristen Protestan, dimana fasilitas ibadah yang tersedia berjumlah 5 buah gereja Kristen Protestan.

\section{Pekerjaan}

Sebagian besar penduduk desa kaneyan bekerja sebagai petani, disamping itu ada juga sebagai pedagang, tukang, buruh, polri, seprti yang terlihat pada tabel.

Tabel 1. Pekerjaan Penduduk Desa Kakas Kaweng

\begin{tabular}{|c|c|c|}
\hline Jenis Pekerjaan & Jumlah (Orang) & $\begin{array}{c}\text { Presentase } \\
(\%)\end{array}$ \\
\hline Petani & 715 & 89,30 \\
\hline Pedagang & 17 & 2,12 \\
\hline Pegawai & 21 & 2,62 \\
\hline Tukang & 32 & 3,99 \\
\hline Buruh & 12 & 1,49 \\
\hline Polri & 4 & 0,49 \\
\hline Jumlah & 801 & 100,00 \\
\hline
\end{tabular}

Tabel 1 menunjukan bahwa pekerjaan penduduk Desa Kakas Kaweng sebagian besar $(89,30 \%)$ sebagai petani yang kemudian tukang, pegawai, pedagang, buruh dan POLRI yang perbandinganya hampir sama.

\section{Karakteristik Petani Cengkeh}

Karakteristik Petani Cengkeh dalam penelitian, mencakup kegiatan ini dilakukan, karena penelitian merupakan proses untuk pengetahuan baru yang menambah informasi, maka perlu adanya data-data baru, pengamatan dan observasi sesuai dengan yang data responden pada penelitian ini.

\section{Umur Petani}

Umur Petani akan mempengaruhi produktivitas dalam bekerja merupakan proses pengambilan keputusan di berbagai alternative pekerjaan yang dilakukan. Umur petani mempengaruhi kemampuan seseorang untuk bekerja secara fisik. Dari hasil penelitian ini didapat umur petani cengkeh yang bervariasi antara petani yang satu dengan petani yang lain disajikan pada Tabel 2.

Tabel 2. Jumlah dan Presentase Petani Cengkeh Responden Menurut Golongan Umur

\begin{tabular}{ccc}
\hline $\begin{array}{c}\text { Umur } \\
\text { (Tahun) }\end{array}$ & Jumlah (Orang) & Presentase (\%) \\
\hline $30-40$ & 4 & 20,00 \\
$41-50$ & 8 & 40,00 \\
$51-60$ & 7 & 35,00 \\
$71-80$ & 1 & 5,00 \\
\hline Jumlah & 20 & 100,00 \\
\hline
\end{tabular}

Sumber: Diolah dari Data Primer

Tabel 2 menunjukan bahwa petani cengkeh yang paling banyak terdapat pada umur 41-50 tahun yaitu 8 orang atau $40,00 \%$ kemudian petani yang berumur 51-60 tahun sebanyak 7 orang atau $35,00 \%$ disusul 30-40 tahun 4 orang atau 20,00\% dan yang paling sedikit adalah umur 71-80 orang atau $5,00 \%$.

\section{Pendidikan Petani}

Pendidikan seseorang mempengaruhi cara berpikir dalam bekerja, diperhitungkan apakah pekerjaan itu menguntukan atau merugikan. Keseluruhan petani responden yang diteliti ternyata paling banyak telah mengenyam pendidikan, untuk lebih jelasnya tentang pendidikan petani cengkeh di Desa Kakas Kaweng dapat dilihat pada Tabel 3.

Tabel 3. Jumlah Presentase Petani Cengkeh Responden Menurut Tingkat Pendidikan Petani

\begin{tabular}{ccc}
\hline $\begin{array}{c}\text { Tingkat } \\
\text { Pendidikan }\end{array}$ & $\begin{array}{c}\text { Jumlah } \\
\text { (Orang) }\end{array}$ & Presentase (\%) \\
\hline SD & - & - \\
SMP & 5 & 25,00 \\
SMA & 13 & 60,00 \\
S1 & 2 & 15,00 \\
\hline Jumlah & 20 & 100,00 \\
\hline
\end{tabular}

Sumber: Diolah dari Data Primer 
Tabel 3 menunujukan bahwa umumnya petani cengkeh berpendidikan menengah atas (SMA) yaitu dengan jumlah 13 orang atau 60,00, setelah itu menyusul pada tingkat SMP 5 orang atau $25,00 \%$ dan diikuti S1 berjumlah 15,00\%.

\section{Produksi dan Harga Cengkeh}

Produksi cengkeh merupakan landasan bagi setiap petani dalam menentukaan memanen atau tidak saat musim bunga cengkeh berlaangsung. Produksi dan haarga cengkeh di Desa Kakas Kaweng dapat dilihat pada Tabel 4.

Tabel 4. Rata-rata Produksi, luas lahan, dan Harga Cengkeh Menurut Responden

\begin{tabular}{ccc}
\hline & Jumlah & $\begin{array}{c}\text { Rata-rata Luas } \\
\text { Lahan (Ha) }\end{array}$ \\
\hline Produksi & $8.677 \mathrm{~kg}$ & 43,3 \\
Luas & $36,3 \mathrm{Ha}$ & 1,8 \\
Harga & Rp.2.121.000 & Rp.106.050 \\
\hline
\end{tabular}

Sumber: Diolah dari Data Primer

Produksi pada tabel di atas menunjukan jumlah $8.677 \mathrm{Kg}$ dengan rata-rata produksi sebesar 43,3 pada keseluruhan responden. Jumlah luas lahan sebesar 36,3 ha dengan ratarata 1,8 ha perpetani dari jumlah responden, dan jumlah harga yang bervariant dari hasil penelitian mendapatkan jumlah keseluruhan harga Rp.2.121.000 dengan rata-rata harga yang di gunakan oleh petani responden sebesar Rp.106.050. Produksi dn luas lahan yang menentukan jumlah satu periode panen juga mempengaruhi fluktuasi harga cengkeh yang dapat memungkinkan petani untuk menyimpan sebagian cengkeh untuk di jual di kemudian hari saat harga cengkeh naik dari harga pada saat masa panen.

\section{Biaya Panen Cengkeh dan Pascaa Panen}

Kegiatan panen dan pasca panen memerlukan biaya, pada umumnya menunujukan pengeluaran yang tercapai dalam kesatuan output yang dihasilkan. Jadi biaya panen cengkeh adalah semua pengeluaran atau biaya yang di tanggung petani untuk panen cengkeh. Penelitian ini hanya menghitung biaya pananen untuk satu kali panen, agar lebih jelas mengenai besarnya kegiatan panen dan pasca panen menurut responden penelitian di Desa Kakas Kaweng adalah sebagai berikut;
Tabel 5. Kegiatan Panen dan Pasca Panen Menurut 20

\begin{tabular}{lcccc}
\multicolumn{5}{c}{ Responden Petani Cengkeh Desa Kaweng } \\
\hline \multicolumn{1}{c}{ Kegiatan } & $\begin{array}{c}\text { Tenaga } \\
\text { Kerja }\end{array}$ & $\begin{array}{c}\text { Jumlah } \\
\text { Kerja }\end{array}$ & $\begin{array}{c}\text { Biaya } \\
(\mathrm{Rp})\end{array}$ & Keterangan \\
\hline Panen & & & \\
\hline Pemetikan & 77 & 420 & 222.352 .500 \\
Pembersihan & 66 & 114 & 53.810 .000 \\
Memasak & 26 & 434 & 21.700 .000 \\
\hline Pasca Panen & & & \\
\hline Penjemuran & 58 & 437 & 21.850 .000 \\
Pembersihan & 15 & 24 & 2.250 .000 \\
Pengepakan & 47 & 56 & 2.800 .000 \\
Memasak & 26 & 437 & 21.700 .000 \\
Transportasi & 11 & 11 & 800.000 \\
\hline Sumber: Diolah
\end{tabular}

Sumber: Diolah dari Data Primer

Kegiatan panen terbagi atas 3 kegiatan yaitu pemetikan dilakukan oleh 77 pekerja dengan cara memetik buah cengkeh yang telah siap panen , setelah buah di petik dilakukan pembersihan dengan 66 pekerja di kebun sebelum memulai untuk pemetikan dan pemisahan antara batang dan buah cengkeh dilakukan, dalam kegiatan panen adapun pekerja yang mempersiapkan konsumsi atau pekerja yang melaksanakan kegiatan memasak sebanyak 26 pekerja untuk para pekerja yang sedang melakukan kegiatan pemetikan dan pembersihan. Kegiatan pasca panen terbagi atas 5 kegiatan yang terdiri dari Penjemuran, Pembersihan, Pengepakan, Memasak, Trasnportasi. Seluruh keggiatan panen dan pasca panen pada Tabel 5 di peroleh dari hasil penelitian pada petani responden di Desa Kaweng.

Tabel 5 menunjukan bahwa rata-rata biaya panen terbesar terdapat pada biaya saat Pemetikan sebesar Rp.222.352.500,- dengan rata-rata Rp.11.117.625,- dan rata-rata biaya terkecil terdapat pada biaya pengemasan sebesar Rp.2.800.000,- dengan rata-rata biaya Rp.106.050,-. Sedangkan biaya tetap yang di keluarkan setiap tahunya oleh para petani di Desa Kakas Kaweng adalah biaya pajak tahunan sebesar Rp.1.866.000,- dengan rata-rata Rp.93.000,- per tahun.

Tabel 6. Rata-rata Biaya Panen Cengkeh Menurut Penggolongan Komponen Biaya tetap dan Biaya Variabel

\begin{tabular}{lrr}
\hline \multicolumn{1}{c}{ Penggolongan Biaya } & Jumlah (Rp) & Rata-rata (Rp) \\
\hline Biaya Variabel : & & \\
Membersihkan Kebun & 53.810 .000 & 2.690 .500 \\
Memetik & 222.352 .500 & 11.117 .625 \\
Menjemur & 21.850 .000 & 1.092 .500 \\
Pengepakan & 2.800 .000 & 140.000 \\
Memasak & 21.700 .000 & 1.085 .000 \\
Perlengkapan Panen & 34.548 .500 & 1.727 .425 \\
Biaya Konsumsi & 3.182 .500 & 159.125 \\
$\quad$ Jumlah Biaya Variabel & 360.243 .500 & 51.463 .357 \\
$\quad$ Biaya Tetap: & & \\
Pajak & 1.866 .000 & \\
Sumber: Diolah dari Data Primer & & \\
\end{tabular}


Biaya-biaya tersebut di keluarkan dalam satu periode panen di Desa Kakas Kaweng Menurut hasil penelitian dengan responden yang ada. Sedangkan biaya per Kg petani dapat dilihat pada Tabel 7:

Tabel 7. Rata-rata Biaya Panen berdasarkan Rata-rata Produksi dan Rata-rata Harga Cengkeh

\begin{tabular}{ccccc}
\multicolumn{5}{c}{ Produksi dan Rata-rata Harga Cengkeh } \\
\hline Jumlah & $\begin{array}{c}\text { Jumlah Biaya Variabel } \\
\text { dan Biaya Tetap }\end{array}$ & $\begin{array}{c}\text { Jumlah } \\
\text { Produksi } \\
(\mathrm{Kg})\end{array}$ & $\begin{array}{c}\text { Rata-rata } \\
\text { Harga } \\
\text { Cengkeh } \\
(\mathrm{Rp} / \mathrm{Kg})\end{array}$ \\
\hline $\mathrm{X}$ & 360.243 .500 & 1.866 .000 & 8.677 & 106.050 \\
\hline
\end{tabular}

Sumber: Diolah dari Data Primer

Dilihat dari Tabel 7 menunjukan bahwa setiap produksi di pengaruhi oleh biaya variaabel dan biaya tetap pada satu kali produksi dengan rata-rata harga cengkeh yang ada pada saat panen, dimana jumlah biaya variabel sebesar Rp.360.243.500,- dan, biaya tetap Rp.1.866.000,- pada rata-rata produksi 43,4 Kg / dengan rata-rata harga Rp.106.050,per $\mathrm{Kg}$ dalam satu periode panen.

Pada Penelitian yang dilakukan di Desa Kakas Kaweng untuk kegiatan Pasca Panen, tidak semua petani responden mengeluarkan Biaya tenaga kerja untuk kegiatan pasca panen, karena sebagian besar kegiatan hanyalah dilakukan oleh pihak keluarga, kegiatan ini pun hanya sekedar membersihkan kebun dan pemilhaaraan, yang dilakukan setiap 3 bulan sekali atau bahkan hanya dilakukan pada saat waktu pembuahan tiba, namun ada juga beberapa petani yang mengeluarkan biaya pada saat pasca panen.

\section{KESIMPULAN DAN SARAN}

\section{Kesimpulan}

Analisis biaya panen dan pasca panen cengkeh di desa Kaweng menurut 20 responden petani menjelaskan bahawa setiap kegiatan mengeluarkan biaya yang bervariasi. hal tersebut dikeluarkan sesuai dengan kebutuhan para petani guna menunjang kegiatan panen dan pasca panen yang di lakukan kurang lebih selama $2-3$ bulan dalam satu periode panen dan pasca panen.

Analisis biaya panen dan pasca panen cengkeh menunjukan bahwa rata-rata biaya terbesar terdapat pada biaya saat Pemetikan sebesar Rp.222.352.500,- dengan rata-rata Rp.11.117.625,- dan rata-rata biaya terkecil terdapat pada biaya pengepakan sebesar Rp.2.800.000,- dengan rata-rata Harga cengkeh Rp.106,050,-. sedangkan biaya tetap yang di keluarkan setiap tahunya oleh para petani di Desa Kakas Kaweng adalah biaya pajak tahunan sebesar Rp.1.866.000,- dengan rata-rata Rp.93.000,- per tahun.

Setiap produksi di pengaruhi oleh biaya variaabel dan biaya tetap pada satu kali produksi dengan harga cengkeh yang ada pada saat panen, dimana jumlah biaya variabel sebesar Rp.360.243.500,- dan, biaya tetap Rp.1.866.000,- pada jumlah produksi $8.677 \mathrm{~kg}$ dengan rata-rata harga Rp.106.050,- per Kg. Biaya-biaya tersebut di keluarkan dalam satu periode panen di Desa Kakas Kaweng Menurut hasil penelitian dengan 20 petani responden.

\section{Saran}

Bagi Para petani cengkeh, sebelum menghadapi masa panen tiba sebaiknya melakukan perencanaan untuk biaya panen secara baik, sehingga produksi dengan harga cengkeh dalam satu periode panen tidak dijadikan landasan untuk menetapkan berapa seharusnya harga dasar cengkeh per $\mathrm{Kg}$. Karena jika para petani sudah dapat menutupi biaya yg dikeluarkan baik pada saat panen dan pasca panen, masih ada sisa untuk memenuhi kebutuhan sehari-hari sampai masa panen selanjutnya.

\section{DAFTAR PUSTAKA}

Hadiwijaya. 1982. Data Cengkeh Dan Petunjuk Kearah Swasembada. Gunung Agung. Jakarta.

Mandei, Laoh dan Wuisan. 2010. Struktur Pengeluaran Rumah Tangga Petani Cengkeh Di Desa Wuwuk Kecamatan Tareran Kabupaten Minahasa Selatan. Artikel. Fakultas Pertanian Unsrat.

Ratung. N. I. 2002. Analisis Biaya Panen Cengkeh di Desa Kombi. (Skripsi). Fakultas Pertanian Unsrat. 